This item was submitted to Loughborough's Research Repository by the author.

Items in Figshare are protected by copyright, with all rights reserved, unless otherwise indicated.

\title{
Bestsellers in the British book industry 1998-2005
}

PLEASE CITE THE PUBLISHED VERSION

PUBLISHER

(c) Springer

LICENCE

CC BY-NC-ND 4.0

\section{REPOSITORY RECORD}

Woodbridge, Hazel, and John P. Feather. 2019. "Bestsellers in the British Book Industry 1998-2005". figshare. https://hdl.handle.net/2134/3134. 
This item was submitted to Loughborough's Institutional Repository by the author and is made available under the following Creative Commons Licence conditions.

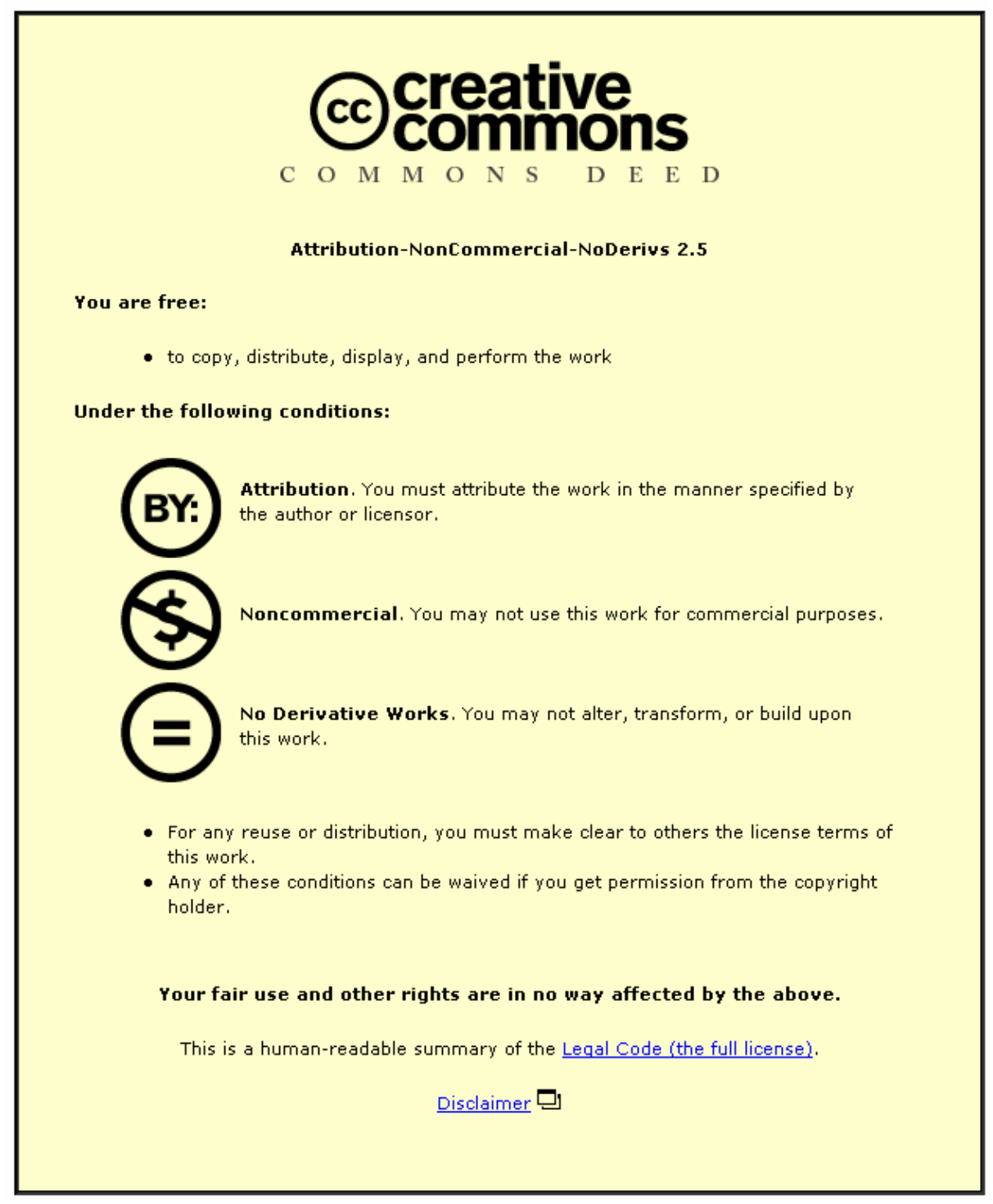

For the full text of this licence, please go to: http://creativecommons.org/licenses/by-nc-nd/2.5/ 
Bestsellers in the British Book Industry 1998-2005

By John Feather and Hazel Woodbridge*

\footnotetext{
* John Feather is Professor of Library and Information Studies, Department of Information Science, Loughborough University, Leicestershire LE11 3TU, UK (Address for correspondence: j.p.feather@lboro.ac.uk); Hazel Woodbridge works for Palgrave Macmillan Ltd., Houndmills, Basingstoke, Hampshire RG21 6XS, UK (Address for correspondence:

H.Woodbridge@palgrave.com).
} 


\section{Introduction}

The bestseller is one of the mainstays of the British retail book trade. The term refers to newly published books which sell in large quantities, and whose sales are recorded in lists which are published in the newspapers and the trade press and through various databases used by the trade. The key consideration here is that the concept is concerned with new publications, not with what is sometimes called a 'longseller', a title which is in print for many years, perhaps even for decades or centuries. The true 'bestsellers' could be argued to be Shakespeare or certain official publications (such as the UK Highway Code which is required reading before taking a Driving Test), or religious books such as the Bible or the Qur'an. These books are all of great commercial significance, but they are typically not recorded in the published lists. The bestseller lists, which reveal so much about changing taste and about the commercial culture of the trade, consist of recent titles which have been selling strongly since their publication. ${ }^{1}$ Indeed, most of the few scholars and commentators who have written on the matter confine themselves even more tightly than this, by assuming or stating that bestsellers are all new fiction. ${ }^{2}$ There are, however, also bestseller lists for non-fiction, and these are also important to the retail trade and hence to publishers.

A closely related phenomenon is that of the tie-in, the book which is the either adapted into some other medium or is a spin-off product from it. Adaptations have a long history; notable early British examples include science fiction novels by John Wyndham, and a number of serialisations of the novels of Dickens, all made for television in the early 1950 s. $^{3}$ The history of film adaptations is even longer. Conan Doyle’s Sherlock Holmes stories spawned 186 films between 1890 and $1984 .^{4}$ The positive effect of a successful adaptation on book sales is well known in the trade and 
to scholars. ${ }^{5}$ The more recent phenomenon of a book generated by a television series has been less systematically studied, but we shall be citing several important examples. ${ }^{6}$ Because media tie-ins are now of such great commercial significance to the book trade, a study of bestselling titles has to include a substantial analysis of this phenomenon.

A detailed historical and contemporary study of British bestsellers in the early 1990s showed a number of key characteristics, including close links with television and other media, and the importance of a small number of hugely popular authors. In broad terms, it was also concluded that the typical fiction bestseller was a paperback while hardback was still the more popular format for non-fiction. Apart from a handful of extremely popular works, the typical fiction bestseller was in the lists for a comparatively short time, while non-fiction had a rather longer shelf-life. ${ }^{7}$ After a decade of radical change in the book trade and the publishing industry, it seemed worthwhile to revisit the subject. In this paper, we report on our findings and make some suggestions about how they should be interpreted. ${ }^{8}$

\section{Sources and methodology}

The most consistently authoritative source of information about bestsellers in the UK is from the lists published each week in The Bookseller, which remains the principal trade publication. ${ }^{9}$ The lists, however, have to be used with caution. Our detailed analysis revealed errors and ambiguities which included inconsistency in the names of titles and authors, and in quoting 'last week's position'. These problems are nevertheless sufficiently rare for them not to have an impact on the statistical validity of this study, although casual users of the published lists should be aware of the need 
to cross-check. The ISBN is probably the best means of ensuring that the same title is actually being listed and discussed.

Our original intention had been to repeat the earlier study for the period since 1996, but changes introduced by The Bookseller itself made this impossible. Since mid-1997 the lists have distinguished between hardback and paperback as well as non-fiction and fiction titles, highlighting the top 15 in each category. Previously, the lists recorded the top 50, which had the effect of overemphasising the dominance of massmarket paperbacks. Hardback fiction particularly suffered from this, since the volume of sales can be small even though some titles are popular and many are profitable. By taking advantage of the more sophisticated data now available, we have been able to drill down to a greater level of detail. We did, however, confine ourselves to the top 10 in each category, partly for practical reasons, and partly to facilitate comparisons with the earlier study.

We recorded author, title, publisher and ISBN, and assigned a genre indicator to each title. ${ }^{10}$ The data was entered into Excel Spreadsheets which were then used to make the statistical analysis. These data related to individual titles. As the basis of a trend analysis at genre level the percentage representation of each genre was calculated as follows:

$\Sigma$ No. weeks each title in the genre features $\Sigma$ No. weeks in the year X 100

This takes account of the number of weeks each genre as a whole features in the lists, and enables comparisons with Reid's findings as he used the same calculation. The 
total number of weeks therefore was not 52 but $52 \times 10,10$ being the 10 possible positions in the list. However, this figure varied from year to year as bank holidays reduced the output of The Bookseller and in few cases lists were not printed. The overall accuracy was therefore maintained by converting the data into percentages to provide valid comparative data.

We also wanted to analyse the phenomenon of the 'tie-in', the book associated with a television programme, a movie or some other medium. To identify these books, we searched various reliable websites, ${ }^{11}$ and listings from DVD stockists. General search engines revealed movie or television versions which are no longer available, or were unsuccessful and long forgotten; in turn this often directed us to an author website, from which we could glean further information. We should remember, however, that some adaptations follow long after publication; in the period under review, the most obvious example is The Lord of The Rings, made into a series of movies in 2001-03 nearly fifty years after the books were originally published in 1954-55. Because of the British focus of the research, adaptations or tie-ins were only included if they were widely available to the British public. ${ }^{12}$ We also established whether the book followed the tie-in, or vice versa.

\section{Findings: fiction}

\section{TABLE 1 NEAR HERE}

It remains the case that general fiction dominates the bestseller lists, with nearly $50 \%$ of the listed mass market fiction, and just under $40 \%$ of original (i.e. hardback) fiction falling under this heading (Table 1). Of the specific categories which were identified, 
the largest was Thrillers, representing about $20 \%$ of the listed fiction in both formats. Although Fantasy, Mystery, Historical Novels and Crime feature strongly, no other category provides $10 \%$ or more of the titles listed. There is some evidence of changing tastes even among these categories. Fantasy is particularly interesting in this regard. While it averages at about $10 \%$ of titles over the whole period, there are peaks and troughs (Figure 1). The growing popularity of Fantasy fiction in the early and mid-1990s was clearly apparent in the earlier study; ${ }^{13}$ it now seems that the popularity of the genre peaked around the year 2000 and it has been in steady decline since then. One possible (but purely speculative) explanation which might be offered is that many of the aficionados of the genre have turned to computer games and other simulations rather than reading as a major leisure activity. ${ }^{14}$ Fantasy nevertheless remained a commercially significant genre in the first years of the new century. ${ }^{15}$

\section{FIGURE 1 NEAR HERE}

The greatest change, however, is in the category of Romance. Except in 1999, romantic novels barely feature in the original fiction lists, and even in the mass market list there are notable annual fluctuations. By contrast, the earlier study found that this genre was one of the most consistently represented. We cannot know whether the findings for 1998 - 2005 are a blip, or show the beginning of a long-term trend (Figure 2). Certainly the declining number of titles of romantic fiction which sell enough copies to feature between positions between 1 and 10 in the bestseller lists is noticeably declining. While in the 1980s and early 1990s, there were never fewer than 10 paperback romance titles in the list every year, with most years registering 12 or more, only one year between 1998 and 2005 saw more than 10 Romance titles, ${ }^{16}$ and by 2005 there was only one. There are several possible explanations for this 
phenomenon, of which the most likely is a relative decline in popularity. ${ }^{17}$ Other categories of fiction have overtaken it, because of an aging readership base which is not being renewed. This hypothesis receives some additional support from the fact that romantic fiction no longer features so strongly among the books most frequently borrowed from public libraries, where it has historically been extremely well represented. ${ }^{18}$ Some in the trade see a revival, ${ }^{19}$ although much of this is the so-called 'chick-lit' which typically takes the reader far beyond the bedroom door which traditionally remained firmly closed. ${ }^{20}$

\section{FIGURE 2 NEAR HERE}

Who writes these massively successful books, and indeed how successful are they? The core list of authors of the most popular fiction changed little for many years. In 1988, they were Catherine Cookson, Wilbur Smith, Jeffery Archer, Dick Francis, Frederick Forsyth, Len Deighton and Barbara Taylor Bradford. Alex Hamilton, a journalist who is an exceptionally knowledgeable commentator on the trade, described them as the 'Formidable Five'. ${ }^{21}$ In 1991, the five authors who had been in every annual list since 1979 were Catherine Cookson, Dick Francis, Danielle Steel, Victoria Holt and Stephen King. ${ }^{22}$ John Grisham joined them in the 1990 s. $^{23}$ There is, however, some evidence of change. In 2004-05, only three of Hamilton's 'Formidable Five' and Grisham were in the top ten most borrowed authors from public libraries (Steel, Grisham and Cookson). None of the others even appeared in the top twenty most borrowed authors of adult fiction. ${ }^{24}$ If the typical public library borrower was becoming less conservative in her (less frequently his) tastes in fiction, the same was certainly true of book buyers. The runaway bestseller of 2004 was The da Vinci Code, 
a book which it is difficult to categorise (fantasy? romance? science fiction?) but which caught the imagination of the public. ${ }^{25}$ In the same year another one-off book became a commercial phenomenon. Mark Haddon's first novel, The Curious Incident of the Dog in the Night-time, sold nearly two million copies worldwide, grossing some $£ 13.7$ million for its publishers. This strange story of an autistic child also crosses the boundaries between genres. It is could be argued to be adult literary fiction, or a children's book. In the latter category (which we are not considering in detail here) it was the bestselling book of the year, but it is probably regarded by readers as an adult book, and as such was an exceptional performer. ${ }^{26}$

Are we looking at evolution or revolution? Of the 'Formidable Five', Holt (one of the pseudonyms of Jean Plaidy) died in 1993, and seems to have dropped off readers' and buyers' radars, ${ }^{27}$ and Francis effectively stopped writing in 2000, although a new title somewhat unexpectedly appeared in $2006 .^{28}$ Danielle Steel on the other hand had twenty-four original fiction titles and twenty-four mass market titles in the lists in the period being analysed here. This suggests that the steady and most predictable bestsellers are actually authors rather than their individual titles, but that further sales are generated by the success of another book. Underlying all this is the close association of author and genre. Genre is arguably the dominant factor in determining popularity. Of the authors who appear most regularly in the bestseller lists in the period, all are associated with a single genre, and most of them with the most popular genres $^{29}$. There is also a noticeable Anglo-American flavour to the list, a factor which deserves further investigation. It is, however, clear that the combination of established author and favoured genre is the basic formula for creating a bestseller.

TABLE 2 NEAR HERE 


\section{Findings: non-fiction}

Non-fiction is more diverse than fiction, yet presents somewhat fewer difficulties in classification. A non-fiction bestseller is in some ways less predictable in terms of authorship, although certain genres clearly dominate the UK market (Table 2). The undiminished human curiosity about other peoples' lives is clearly reflected in the popularity of autobiographies and biographies, a phenomenon which remains essentially unchanged since the previous study. ${ }^{30}$ Other categories reflect fashions and phenomena of the period. The celebrity chef, with his or her television series, was one of the stranger manifestations of British social life at the turn of the twenty-first century. ${ }^{31}$ At a time when cooking and eating at home was actually in decline, cookery books were a major publishing success; they were the kitchen equivalent of the coffee-table art books of the 1960s and 1970s. Moreover, they were typically in hardback (a concession perhaps to the possibility of actually using them), and were commercially valuable property. Diet books, on the other hand, retained essentially the market share which they had enjoyed a decade earlier, despite the phenomenal success of the Atkins diet and its many associated books, including Atkins's own continuing publications until his death in 2003. Health and fitness books fared even worse; they barely held their market share. Most of the subject categories recorded in Table 2 are so small that it is difficult to draw conclusions about them. They reflect, at least in part, the wide-ranging interests of the British public. The real significance of these data only becomes clear when we turn to the issues of the media tie-ins.

\section{The tie-in phenomenon}

As we have seen, tie-ins and spin-offs have a long history, but they have become a major phenomenon in the last decade. In broad terms, we can distinguish between 
two categories of tie-in: the adaptation (typically fiction) and the spin-off (typically non-fiction). It is well established that the serialisation of a book, even of a classic, can propel it into the bestseller lists or at least substantially increase its sales. Recent British examples include BBC adaptations of Pride and Prejudice (first broadcast in 1995) and Bleak House (first broadcast in 2005). ${ }^{32}$ But the effect can be at least as powerful for contemporary fiction; of the recent examples, perhaps the most notable is Alan Hollinghurst's The Line of Beauty (2006). ${ }^{33}$ The spin-off book derives from a series and is typically published simultaneously with the first broadcast run; recent examples include Simon Schama's The Power of Art (broadcast in October-November 2006), and Franceso da Mosto’s Venice (broadcast in 2004). ${ }^{34}$ Finally, we cannot ignore the related phenomenon of television programmes which promote books and their authors. In the UK, the most important of these is Richard and Judy's Book Club, a show which, since it was first broadcast in 2001, has had a profound influence on the British book trade. One contemporary commentator has described the two presenters (Richard Madeley and Judy Finnegan) as 'the most powerful people in British publishing, ${ }^{35}$ Authors as distinguished as Andrew Motion, the Poet Laureate, and Julian Barnes, one of the finest novelists of his generation, pay respects to them, praising them for raising the profile of books and encouraging both reading and buying. ${ }^{36}$ The comparison with Oprah Winfrey was inevitable but not inappropriate.

About $20 \%$ of fiction bestsellers are television tie-ins, with a strong emphasis on fantasy and autobiographical fiction (29\% and 18\% respectively of the titles in the hardback lists for these categories) (Table 3). In some of the key categories in the fiction market, the relationship with television is very close indeed, notably in crime, thrillers and fantasy. In others it is less so. But the importance of the phenomenon is 
beyond question. With non-fiction, the position is more complicated, as might be expected. About $25 \%$ of the titles in the hardback bestseller lists in the period were television tie-ins, together with about $15 \%$ of paperbacks. This can be largely explained (one might say, was distorted) by the phenomenon of the celebrity chef which we have already noted. Nearly half of the hardbacks which appeared in the bestseller lists in the Cookery Food \& Drink category were television tie-ins; no other category reached $10 \%$ in hardback, and only autobiography, travel and the ubiquitous 'other' did so in paperback (Table 4).

TABLE 3 NEAR HERE

\section{TABLE 4 NEAR HERE}

Television is, of course, the predominant tie-in medium for books, but there are others. One new phenomenon of the period under review, already noted by Sutherland, ${ }^{37}$ is the computer game. All the game tie-in books in the lists actually began as games in the period studied; this is a phenomenon which publishers, authors and agents will continue to watch carefully. It is, however in the field of non-fiction that we find the greatest variety of tie-in media. In addition to television, we have radio, television, newspapers, magazines, movies and DVDs. Although the variety is greater with paperbacks than it is with hardbacks, it is observable even among the latter (Figure 3). 
Nevertheless, television remains the dominant tie-in medium. Almost all the hardbacks represented in the data, and roughly half of paperbacks, were published simultaneously with the first broadcast of the television programme or (more usually) series. This is particularly important for non-fiction, since, with rare exceptions, the books rapidly lose their interest when the television series is complete. Predictably, BBC Books was the predominant publisher of such books.

\section{FIGURE 3 NEAR HERE}

\section{The current position}

The data which permit the detailed analysis which forms the basis of the bulk of this paper is only published retrospectively. The study was undertaken with the latest data available at the time. But it is instructive in the light of our findings to consider the position by taking a snapshot in 2007. We begin, however, with the Christmas season of 2006. This has been a critical season for British publishers and booksellers since Dickens began to publish his Christmas Books in the 1840s. In recent years, there has a been a distinct phenomenon of the unlikely success, some perhaps carefully chosen in the hope that it would be the unexpected bestseller of the season. Lynne Truss's Eats, Shoots and Leaves, a book about grammar and punctuation achieved this feat in 2004, and perhaps set the pattern. The book had a serious subject - the decline of the proper use of syntax and punctuation by English speakers and writers - but it was entertainingly written, well-illustrated with clever cartoons, and generally lighthearted in its approach to a serous subject. ${ }^{38}$ It was published by a small independent publisher, Profile Books, and was partly responsible no doubt for the house being Small Publisher of the Year for 2004. ${ }^{39}$ The Truss book was followed in subsequent 
years by books which were compendia of amusing factual data, and in 2006 by the least likely of all. This was Harry Mount's Amo, Amas, Amat...and all that, an entertaining introduction to Latin. ${ }^{40}$ Improbable as that may seem, it was already selling 1,000 copies a week in November, and was still selling on Christmas Eve. Again, the publisher was small and comparatively new. Short Books was founded by two former journalists (Mount's own profession) in 2001; this was their first significant commercial success. $^{41}$

These were maverick successes, perhaps more easily achieved by small independent publishers than by the major corporations. In Spring 2007, familiar patterns can still be seen in the mainstream. Authors in the paperback fiction list included Daneille Steel and Patricia Cornwell, although there was a also a sprinkling of newer (and typically younger) writers including C J Sansom. Hardback bestsellers in the same week included new books by Wilbur Smith, Ian McEwan and Alexander McCall Smith, the latter a middle-class cult of the last 5 years, ${ }^{42}$ as well as a newly discovered and edited work by J R R Tolkien. Among the general hardbacks, celebrities continue to dominate, including books (some ghosted) by the wife of a celebrity footballer, the former editor of a tabloid newspaper, show business memoirs, and the reminiscences of a former SAS soldier who has become a television personality. Paperback nonfiction shows much the same obsession with celebrity and the media. ${ }^{43}$ Some of the names may change, but the patterns are constant and predictable.

\section{Some conclusions}

The influence of television on the book trade is apparent even to the casual observer. Closer analysis, however, shows that the two industries are now inextricably 
interlinked. Tie-ins in both directions (adaptations and spin-offs), the phenomenal influence of television book programmes, and the power of marketing have combined to transform the book trade at the beginning of the twenty-first century. This, of course, mirrors the structure of the trade itself. It is international, and it is dominated by global corporations. These dominant players are involved in many media, and indeed for some of them book publishing is a comparatively small part of the business. But it remains an important part, for it gives them access to another format in which to exploit the content in which they have intellectual property rights. The bookselling business has also changed; the changes were as profound as in publishing, although rather more domestic. The de facto abolition of the Net Book Agreement in 1997 transformed the British book trade. For the first time in nearly a century, there was price-based competition between booksellers. The increasingly dominant bookselling chains took full advantage of this. They offered reduced prices, deals such as three books for the price of two, and so on. The volume of books sold increased, and almost all of this increase was at the popular end of the market. ${ }^{44}$ It was the bestsellers, and the authors and genres which populate the bestseller lists, that benefited most from these changes.

At the lowest estimate, books are valuable sources of content for television, movies, computer games and other tie-ins. They are an additional outlet for content which originates in another medium. But they are also a profitable an successful format in their own right. We have found that there is continuity as well as change in the British book trade as it is reflected in its best-selling titles. General fiction and thrillers continued to be two of the dominant genres in the bestseller lists, with crime and mystery books still holding their market share. Autobiographies, biographies, 
cookery, history, sport, and travel books continually occupy the non-fiction lists. These findings essentially mirror those in earlier studies.

There have, however, been changes, perhaps reflecting the changing demographics of reading. Fantasy has become more popular, and romance has lost some of its appeal; there is almost certainly an age phenomenon at work here, as an older generation which read romances is replaced by a younger generation with different tastes. At the other end of the scale, the appeal of fantasy to young people (and some not-so-young people as well) is a well-attested phenomenon across all the media. Fads and fashions also have an impact in both fiction (Harry Potter, or the Tolkien revival) and nonfiction (celebrity chefs and footballers). There is still no certain way to identify a potential bestseller. Books can be written to formulae, and yet they can fail. Others can be outside any recognisable pattern, and yet achieve phenomenal success. That might even be taken as a measure of the vitality of the book trade and the commitment of its customers. 
Table 1

Fiction 1998-2005: \% of titles

\begin{tabular}{|c|c|c|}
\hline Category & Mass market & Original \\
\hline Adventure & $>1$ & 1 \\
\hline Autobiographical & 4 & 2 \\
\hline Crime & 5 & 8 \\
\hline Fantasy & 7 & 9 \\
\hline General & 48 & 39 \\
\hline Historical & 5 & 8 \\
\hline Humorous & 2 & 3 \\
\hline Horror & $>1$ & $>1$ \\
\hline Literary & 0 & $>1$ \\
\hline Mystery & 7 & 8 \\
\hline Romance & 3 & 4 \\
\hline Science Fiction & $>1$ & 20 \\
\hline Thrillers & 21 & 2 \\
\hline
\end{tabular}


Table 2

Non-Fiction 1998-2005: \% of titles in selected categories

\begin{tabular}{|c|c|c|}
\hline Category & Hardback & Paperback \\
\hline Art & 1 & $<1$ \\
\hline Autobiography & 28 & 28 \\
\hline Biography & 8 & 5 \\
\hline Cookery, Food \& Drink & 20 & 3 \\
\hline Diet books & $<1$ & 6 \\
\hline DIY (Home improvement) & 2 & $<1$ \\
\hline Documentary books & 2 & 3 \\
\hline Gardening & 2 & 1 \\
\hline Guide books & 1 & 3 \\
\hline Health & 3 & 8 \\
\hline History & 4 & 6 \\
\hline Humour & 3 & 4 \\
\hline Nature & 1 & 2 \\
\hline Poetry & 2 & 2 \\
\hline Politics & 2 & 3 \\
\hline Reference & 7 & 12 \\
\hline Religion & 2 & 1 \\
\hline Royalty & 2 & $<1$ \\
\hline Science & 4 & 3 \\
\hline Sport & 4 & 1 \\
\hline Travel & 4 & 7 \\
\hline War & 1 & 1 \\
\hline Other & 4 & 7 \\
\hline
\end{tabular}

Categories which have less than $1 \%$ representation in both hardback and paperback are omitted. 
Table 3

Fiction Tie-ins 1998-2005: \% of titles in selected categories

\begin{tabular}{|c|c|c|}
\hline Category & Mass market & Original \\
\hline Autobiographical & 18 & 11 \\
\hline Crime & 10 & 4 \\
\hline Fantasy & 25 & 21 \\
\hline General & 29 & 14 \\
\hline Historical & 11 & 10 \\
\hline Horror & 11 & 5 \\
\hline Mystery & 3 & 2 \\
\hline Science Fiction & 9 & 0 \\
\hline Thrillers & 8 & 9 \\
\hline
\end{tabular}

This Table shows the percentage of titles in the bestseller lists which were TV tie-ins, omitting those categories where that figures is less than $1 \%$. 
Table 4

Non-fiction Tie-ins 1998-2005: \% of titles in selected categories

\begin{tabular}{|c|c|c|}
\hline Category & Hardback & Paperback \\
\hline Art & 0 & 2 \\
\hline Autobiography & 1 & 28 \\
\hline Biography & 2 & 3 \\
\hline Cookery, Food \& Drink & 48 & 5 \\
\hline Documentary books & 5 & 6 \\
\hline Gardening & 6 & 3 \\
\hline Health & 5 & 8 \\
\hline History & 9 & 4 \\
\hline Nature & 3 & 2 \\
\hline Reference & 0 & 5 \\
\hline Science & 5 & 6 \\
\hline Travel & 5 & 11 \\
\hline War & 4 & 0 \\
\hline Other & 9 & 24 \\
\hline
\end{tabular}

This Table shows the percentage of titles in the bestseller lists which were TV tie-ins, omitting those categories where that figures is less than $1 \%$. 
Figure 1

Fantasy: 1998-2005: \% of titles annually

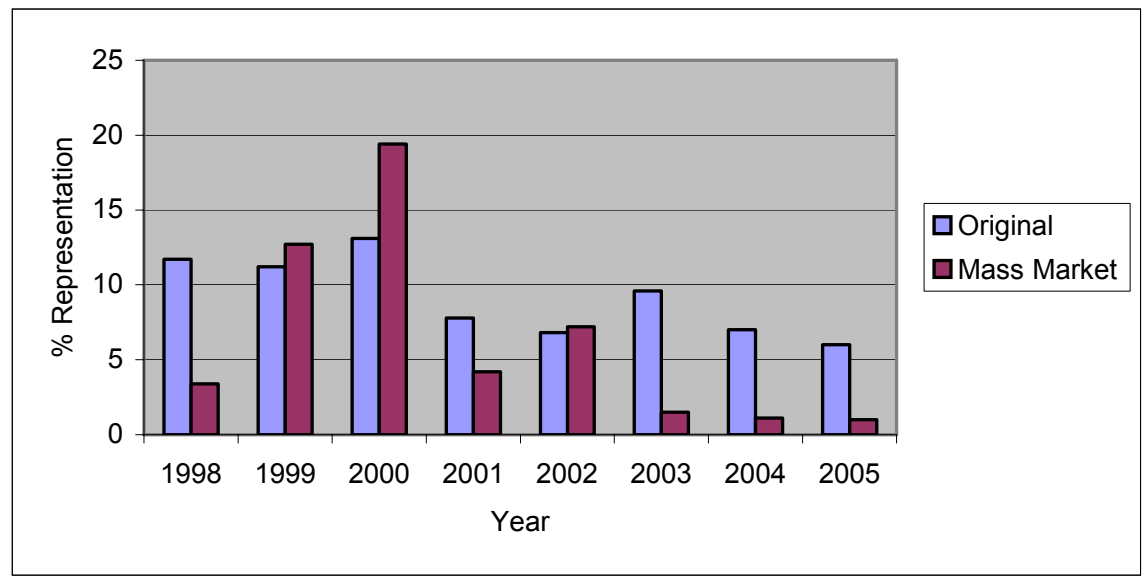

Page 20 of 25 
Figure 2

Romance: 1998-2005: \% of titles annually

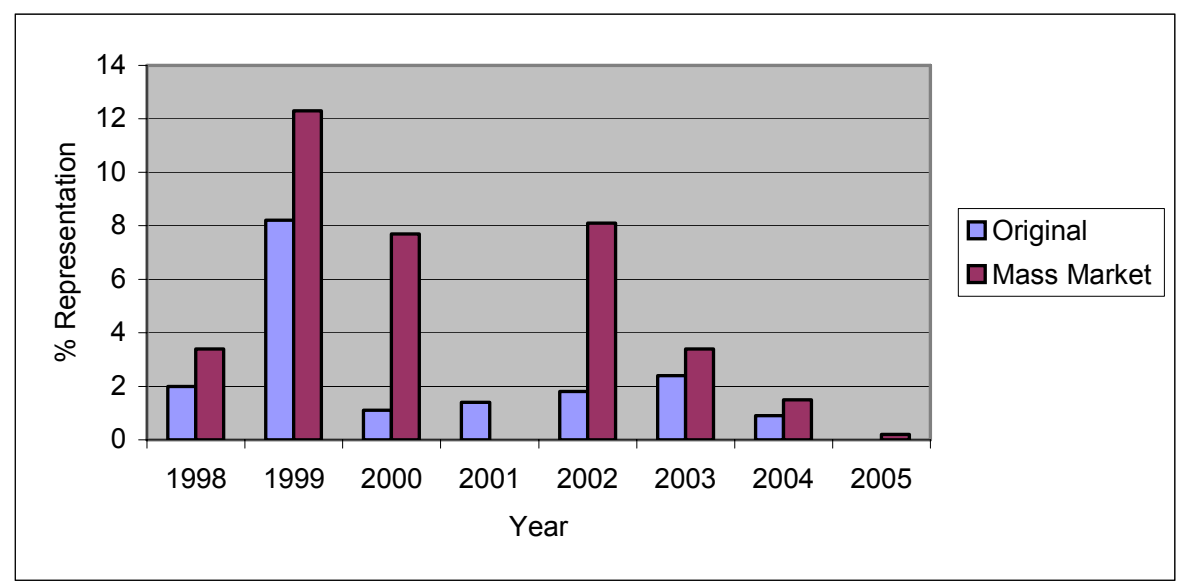


Figure 3

Non-fiction tie-ins: media employed
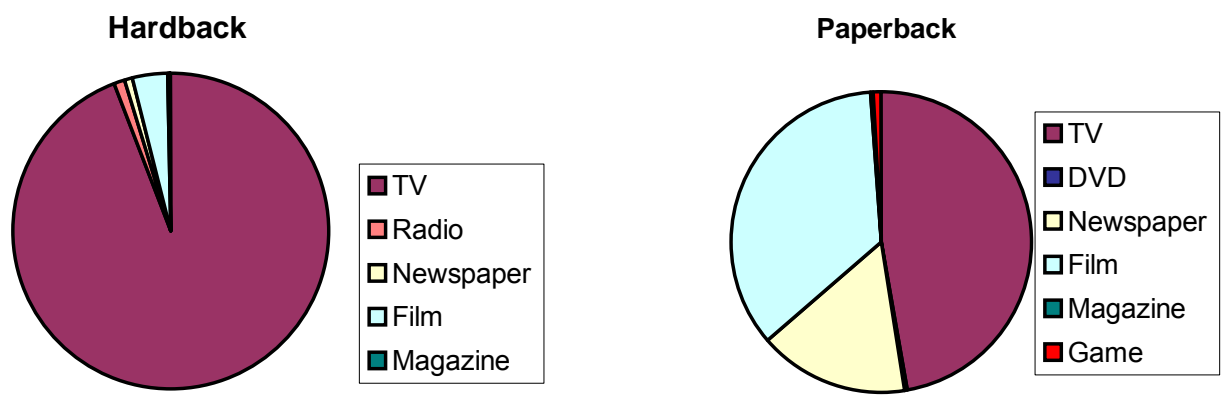


\section{References}

${ }^{1}$ Sutherland, (2002). pp. 7-8. Substantially revised editions of standard works such as dictionaries are included, but these can be argued to be 'new' books for commercial purposes.

${ }^{2}$ Bloom, (2002), p. 6, which defines a bestseller as ' the work of fiction sold in the most units'.

${ }^{3}$ Bloom, (2002), p. 100. See also http://us.imdb.com/name/nm0002042 <accessed 29.09.06> for Dickens adaptations.

${ }^{4}$ Robertson, (1985), p. 46. Sherlock Holmes was first portrayed on screen in 1893 (see http://www.holmesonscreen.com/indexFPGallery.htm <accessed 29.09.06>.

${ }^{5}$ Storry and Childs (2002) p. 92; and Feather (2006), pp. 209-10.

${ }^{6}$ See, however, Sutherland, (2002), pp. 163-4.

${ }^{7}$ Feather and Reid (1995), 57-72.

${ }^{8}$ The work was undertaken in the 2005-06 academic year by HW as the basis for her final year undergraduate project at Loughborough University, under the supervision of JF. We are jointly responsible for this paper.

${ }^{9}$ Now also online at http://www.thebookseller.com

${ }^{10}$ The genres (following Feather and Reid (1995)), were as follows:

Fiction: Adventure, Autobiographical, Crime, Fantasy, Historical, Horror, Humorous, Literature, Mystery, Romance, Science Fiction and Thrillers.

Non-fiction: Art, Autobiography, Business and Management, Cookery Food and Drink, Dictionaries, Diet books, DIY, Documentary, Gardening, Guide Books, Health, History, Humour, Nature, Poetry, Politics, Religion and spirituality, Royalty, Science, Sport, Travel, War and Military, and others.

${ }^{11}$ Notably http://www.bbc.co.uk/films/film2006/

12 This rule caused the exclusion, for example, of the Norwegian film of Sophie's World which was not released worldwide (Sofies verden released in 1999; see http://imdb.com/title/tt0125507/, <accessed 29.09.06>, whereas most Northern American films are of course easily accessible, and were indeed taken into account.

${ }^{13}$ Feather and Reid, (1995) p. 64-5, Tables 3, 4.

${ }^{14}$ Barrell (2003).

${ }^{15}$ Clee (2004).

${ }^{16}$ The detailed data which underpinned Reid and Feather, from which this is derived, is available only in Reid's unpublished dissertation: Reid (1993).

${ }^{17}$ There may have been some marginal differences in classifying certain works, but this cannot explain the disparity. The difficulties of classification are discussed by Sutherland (2006), pp. 26-27.

${ }^{18}$ See the UK Public Lending Right website at www.plr.uk.com/, and the detailed analysis by author and title in LISU (2005).

${ }^{19}$ Bone (2005). 


\section{${ }^{20}$ Brown (2006).}

${ }^{21}$ Feather and Reid (1995), pp. 70-71.

${ }^{22}$ Sutherland (2002), p. 170, citing Alex Hamilton who described the group as the 'Formidable Five’.

${ }^{23}$ Suitherland (2002), p. 171.

24 ‘Most borrowed authors’, www.plr.uk.com < accessed 18 October 2006>.

${ }^{25}$ Hamilton (2005a)

${ }^{26}$ Hamilton (2005b), an article about the best selling children's books of 2004; but significantly, it is not among the most borrowed children's books from public libraries in the year of its publication, or the following year (www.plr.uk.com $<$ accessed 18 October 2006>).

${ }^{27}$ www.fantasticfiction.co.uk/p/jean-plaidy <accessed 18 October 2006>. Neither Plaidy noir any of her pseudonyms appears in the 2004-05 PLR lists.

${ }^{28}$ http://www.fantasticfiction.co.uk/f/dick-francis $<$ accessed 18 October 2006>.

${ }^{29}$ These include, for example, Catherine Cookson (romance), Bernard Cornwell (thriller), Patricia Cornwell (crime), Clive Cussler (thriller), John Grisham (thriller), Stephen King (fantasy), Andy McNab (thriller), Terry Pratchett (fantasy), Ian Rankin (crime).

${ }^{30}$ Feather and Reid (1995), p. 63.

${ }^{31}$ Humble (2005).

${ }^{32}$ See http://www.bbc.co.uk/drama/prideandprejudice/ and http://www.bbc.co.uk/drama/bleakhouse/ $<$ both accessed 18 October 2006>

${ }^{33}$ See http://www.bbc.co.uk/drama/lineofbeauty/ <accessed 18 October 2006>.

${ }^{34}$ See www.bbc.co.uk for these two programmes < accessed 19 October 2006>.

35 Jeffries (2004)

${ }^{36}$ Fernand (2006).

${ }^{37}$ Sutherland, (2002), p. 153.

${ }^{38}$ The title (on which the cover illustration is based) refers to a giant panda which goes into a bar. It has a meal, fires a gun and goes away. Without the comma it engages in its more usual activity of living on bamboo.

${ }^{39}$ http://www.profilebooks.co.uk/ <accessed 30 January 2008>.

${ }^{40}$ In the 2005 Christmas season, Albert Jack, Red Herrings and White Elephants, sold over 80,000 copies; it was book which explained the origins of popular phrases. In the same year, Amazon sold twice as many copies of Does Anything Eat Wasps and 101 Other Questions as it did of The Da Vinci Code in the same season in the previous year. This is a compilation of answers to readers' queries in the (serious but popular) New Scientist weekly. See Which book (2006). There was a Times leader on the book - and the subject - on the same day.

${ }^{41}$ http://www.shortbooks.co.uk/ <accessed 30 January 2008>.

${ }^{42}$ See http://www.mccallsmith.com/ <accessed 30 January 2008>. 
${ }^{43}$ See the lists for 13 May 2007 at

http://entertainment.timesonline.co.uk/tol/arts_and_entertainment/books/article1767224.ece <accessed 30 January 2008>.

${ }^{44}$ Dearnley and Feather (2002). 